Artime Pinilla, Joaquín.

Doctorando en Arte: Investigación y Producción, Becario FPI, Universitat Politècnica de València, Departamento de Escultura, Laboratorio de Creaciones Intermedia.

\title{
Referentes invertidos: intervención artística, teoría queer y literatura
}

\section{Referentes invertidos: art intervention, queer theory and literature}

TIPO DE TRABAJO: comunicación.

PALABRAS CLAVE

Intervención artística, biblioteca, arte, literature, queer, gay.

KEY WORDS

Art intervention, library, art, literature, queer, gay.

RESUMEN

Este artículo es un análisis del trabajo teórico y creativo que da como resultado la intervención artística Referentes invertidos. Inaugurada el 26 de abril de 2018 como una obra más de la exposición colectiva Biblioteca en paral/lel, proyecto ganador de un PAC (Propuesta de Acción Cultural), una ayuda que concede el Àrea d’Activitats Culturals de la Universitat Politècnica de València.

Este site specific se insertó en el edificio de la Biblioteca Central de la Universitat Politècnica de València. En sus cristaleras se escribió con rotulador de tiza en grandes dimensiones los apellidos de tres escritores que, en habla española, catalana e inglesa, reivindicaron activamente su condición de hombres gays, visibilizando y estableciendo otros imaginarios sobre las relaciones afectivas, amorosas y sexuales.

Cada uno de los apellidos -Burroughs, Moix y Lemebel- se construyó con los títulos de las obras literarias que sus autores dejaron como legado. Se escribieron con un color secundario y al revés, para aludir al insulto "invertido", reclamar la procedencia de unos escritores que han creado desde el margen, perteneciendo a una minoría, y así poner en valor su producción literaria, su importancia histórica y sus aportaciones al mundo de las letras.

Con la elección de estos autores, el empleo de conceptos como la apropiación, la metodología artística usada, la escritura a mano y el color, se genera un espacio que vincula arte y literatura, así como visibiliza escritores clave en la producción de relatos propios al mundo queer.

\section{ABSTRACT}

This article is an analysis of the theoretical and creative work which resulted in the artistic intervention Referentes invertidos (Inverted Referents) inaugurated on $26^{\text {th }}$ April 2018 as one of the works of the collective exhibition Biblioteca en paral.lel (Parallel Library), a winning project of a PAC (Propuesta de Acción Cultural / Cultural Action Proposal), a financial help conceded by the Área d'Activitats Culturals de la Universitat Politècnica de València (Area of Cultural Activities of the University of Valencia).

This specific site was located in the building of the Central Library of the Polytechnic University of Valencia. On its windows using a chalk marker were written in letters of large dimensions the surnames of three writers who, in Spanish, Catalan and English, actively re-vindicated their condition of being gay men, highlighting and establishing other imaginaries about sentimental, amorous and sexual relations. 
Each one of the surnames -Burroughs, Moix and Lemebel- was produced with the titles of the literary works that their authors left as a legacy. The names were written in a secondary colour and back to front to allude to the insult "invertido" (in Spanish "invertido" / "inverted" can be used as an insulting reference to a male homosexual)_and to highlight the origin of some writers who have created from the sidelines, belonging to a minority, and in this way place value on their literary production, their historic importance and their contributions to the world of the arts.

The choice of these authors, the use of concepts such as appropriation, the artistic methodology used, the handwriting and the colour creates a space that links art and literature, as it does create awareness of writers, the key in the production of stories peculiar to the queer world.

\section{INTRODUCCIÓN}

El 26 de abril de 2018 se inaugura en la Biblioteca Central de la Universitat Politècnica de València la exposición colectiva Biblioteca en paral/lel, un proyecto que cuenta con una de las ayudas a las Propuestas de Acción Cultural que ofrece el Àrea d'Activitats Culturals de la misma universidad.

Esta muestra consiste en una serie de intervenciones artísticas en el edificio de la Biblioteca Central ${ }^{1}$ de dicha universidad, ocupando espacios que no están ideados para exponer arte. Se concibe como una actividad más dentro de la semana del Día del Libro. Profesoras/es, doctorandas/os y alumnas/os de la Facultad de Bellas Artes realizan obras inéditas y ex profeso que inciden en posibles relaciones entre el libro, las letras y las artes visuales. Joaquín Artime, Pilar Crespo, Salomé Cuesta, Mar Juan, Sara Vilar, Pepe Romero y Rafa Rodríguez producen seis obras, de diferentes disciplinas y técnicas ${ }^{2}$, para crear un nuevo contexto que invita al espectador a otros ritmos y actitudes, a otras formas de entender el acto expositivo, de ocupar el espacio. $Y$ acercan el trabajo que se desarrolla en la facultad a toda la comunidad universitaria.

En este marco, surge Referentes invertidos, un site specific realizado en las cristaleras de la sala de principal de la biblioteca. Con letras mayúsculas se confecciona los apellidos de tres escritores que, en distintas lenguas, español, catalán e inglés, visibilizaron su condición de hombres gays, reivindicando y asentando otros tipos de imaginarios sobre las relaciones afectivas, amorosas y sexuales que mantienen hombres con hombres.

Este artículo es un análisis del trabajo teórico y creativo que trata la elección de estos autores, el empleo de conceptos como la apropiación, la metodología artística usada, la escritura a mano y el color. Con todos ellos se compone un espacio que vincula arte y literatura, así como visibiliza escritores clave en la producción de relatos propios del mundo queer.

\section{DESARROLLO}

\section{Antecedentes: Letanías. Y de cómo darle continuidad a MARICÓN}

Ante la oportunidad de crear una intervención en la biblioteca, tenemos claro que queremos darle continuidad a Letanías, un proyecto que desarrollamos desde 2013 y que a lo largo de los años ha evolucionado. En esta serie el centro de nuestro interés recae en el lenguaje y sus problemáticas al comunicarnos. Plásticamente producimos una escritura a mano con letras mayúsculas, sin espacios y sin signos de puntuación. Sobre una misma superficie repetimos una frase una y otra vez. Como muchas de las superficies que intervenimos suelen ser de cristal, dependiendo de la posición del espectador, éste puede leerlas al derecho o al revés, aunque están construidas para que en el primer encuentro el texto se presente con una lectura hacia atrás.

\footnotetext{
${ }^{1}$ Hemos de tener en cuenta que este espacio se destina principalmente a la consulta, el préstamo, el archivo y la conservación de material bibliográfico y la divulgación del conocimiento académico. La biblioteca de cualquier universidad, con la selección de sus fondos, es un retrato del colectivo que la usa.

${ }^{2}$ Entre las que se encuentran una performance, tres intervenciones, una instalación y una obra de net-art.
} 

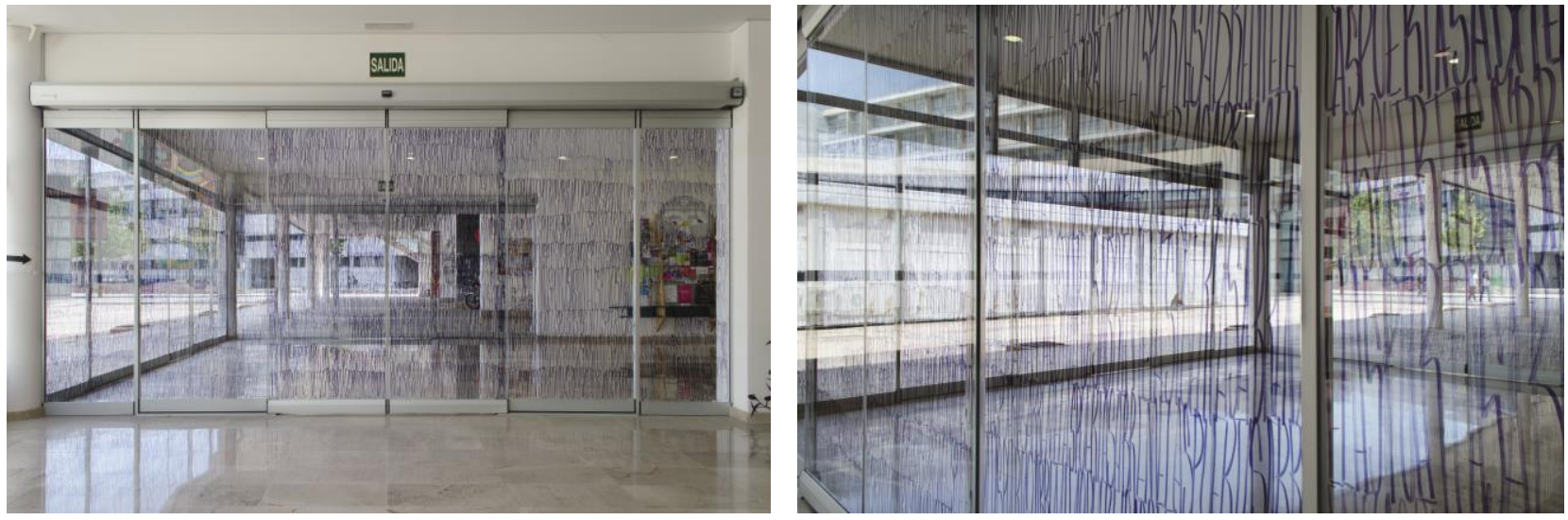

Figura 1A y 1B. Joaquín Artime, Ábreme las puertas (2015). Intervención en el Hall de la Facultad de Bellas Artes de San Carlos. Universitat Politècnica de València. Rotulador permanente sobre cristal.

En los últimos años hemos construidos grandes letreros con esta metodología de trabajo. Es el caso de MARICÓN (2017). Cuando se nos invita a elaborar una intervención en Cocentaina (Alicante) con motivo de la celebración del orgullo de la localidad, nos vino a la mente Carmelo Gabaldón y su intervención \#SOYMARICÓN${ }^{3}$ (2017). Cuando esta obra suscita polémica ${ }^{4}$, para nosotros subraya la urgencia de activar muchas más propuestas que incluyesen el término como empoderamiento y grito de guerra. Apropiarse de este insulto para arrebatarle su capacidad hiriente y visibilizar el término, ya que la palabra "gay" ha dejado de representar a un colectivo agraviado por la homonorma ${ }^{5}$.

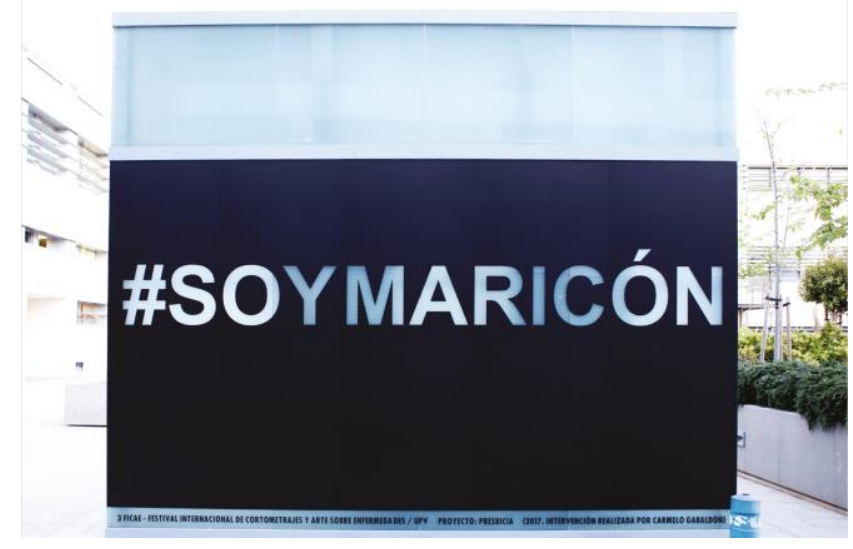

Figura 2. Carmelo Gabaldón, \#SOYMARICÓN (2017). Intervención en el espacio público. Universitat Politècnica de València. Vinilo acrílico adhesivo y luz. 330 x $550 \mathrm{~cm}$.

Compartiendo esta lucha, abordamos una de las primeras piezas que deja clara nuestra condición sexual. En la fachada acristalada del Centre Cultural El Teular construimos la palabra "maricón" en mayúsculas. Rellenamos las letras escribiendo en su interior palabras que nombran distintas tribus gays: twinks, nutrias, osos, pups, leathers, daddies, cachorros, locas, bakalas, lobos, chasers y un largo etcétera ${ }^{6}$. Nos preguntamos cuáles los criterios de clasificación y si éstos son necesarios. Concluimos que quizás responden a una

\footnotetext{
${ }^{3}$ En el 3 Festival Internacional de Cortometrajes y Arte sobre Enfermedades (2017) Carmelo Gabaldón es invitado a participar en una sección llamada Presbicia, que ese año trataba la homofobia como una enfermedad social (Gabaldón, 2018). Un gran vinilo negro cubre un lucernario que se encuentra a la intemperie, en la Universitat Politècnica de València, en negativo, se puede leer el hahstag \#SOYMARICON.

${ }^{4}$ La univerisidad inicialmente censuró la propuesta. Al filtrarse en prensa lo acaecido, finalmente rectificó, se produjo y exhibió la obra.

5 "La homonormatividad sería una normatividad derivada de la hegomnía heterosexual. Se trataría de aquella política homosexual que apoya abiertamente la cultura heterosexual dominante, aceptando su hipótesis y aspirando a ser parte de sus instituciones" (Rivas San Martin, 2018, p. 110).

${ }^{6}$ En la búsqueda para completar este listado descubrimos que existe una web en la que, introduciendo aspectos físicos, un algoritmo "ayuda" a ubicar a los usuarios gays dentro de una de estas "familias". Esta página, consultada en junio de 2017, www.studiomoh.com/fun/census/results.php, ya no está operativa. Realizando una nueva búsqueda encontramos un artículo de la revista Shangay, "¿A qué tribu perteneces?", que recoge imágenes de los gráficos a los que nos referimos. En https://shangay.com/2015/02/11/a-que-tribu-gay-perteneces/ (consultado el 3 de abril de 2019).
} 
desvirtuación machista dentro de un colectivo que sufre plumofobia, donde los hombres se hipermusculan en busca de otros hombres igual de musculados, igual de "masculinos", igual de "discretos" - como si todos ellos fuesen sinónimos-.

Nuestro MARICÓN se inserta en la fachada del Centre Cultural El Teular para ser leído al derecho, mientras las tribus que conforman cada una de las letras están escritas al revés, enunciando de esta manera un divorcio de sentidos, afectos y representatividades.
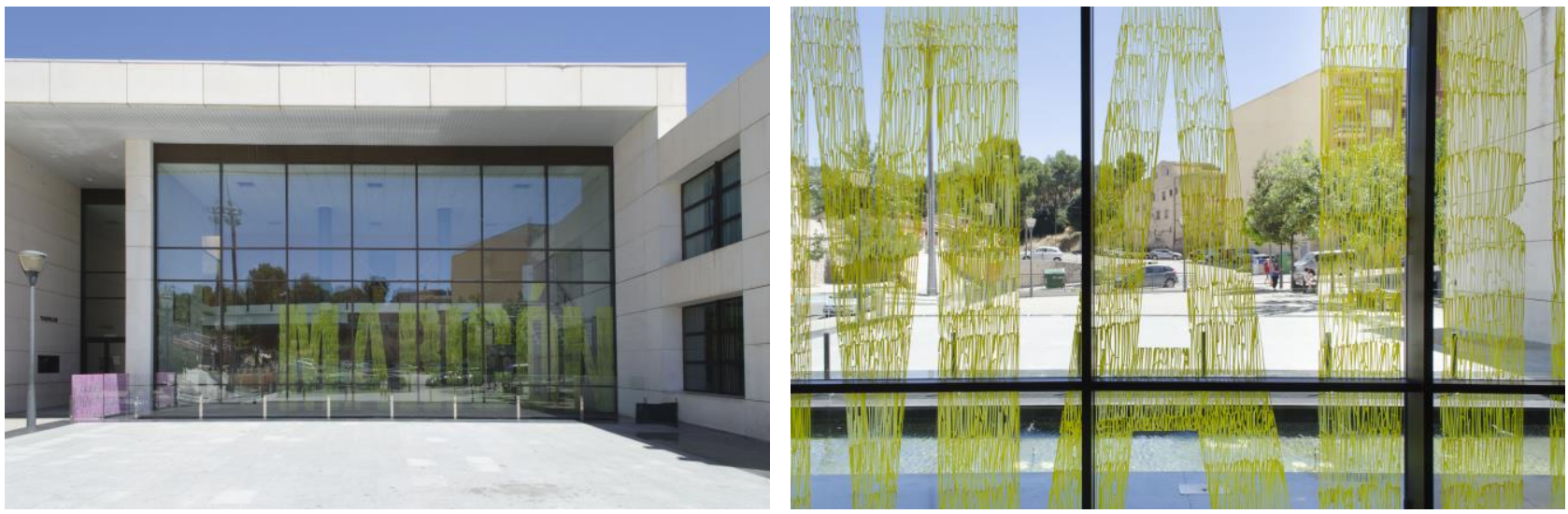

Figura 3A y 3B. Joaquín Artime, MARICÓN (2017). Intervención en el Centre Cultural El Teular, Cocentaina, Alicante. Rotulador amarillo y rosa sobre cristal.

\section{Unos pocos apuntes de teoría queer. Los maricones como sujetos abyectos}

Beatriz Preciado en Multitudes queer. Notas para una política de los anormales (2003) describe la heterosexualidad como un "régimen político, que forma parte de la administración de los cuerpos y de la gestación calculada de la vida, es decir, como parte de la 'biopolítica'" (p. 158). La homosexualidad es una noción medicalizada del S. XIX que define las prácticas sexuales. Este término se abandona a favor de una definición política y estratégica de las indentidades queer.

El origen de la palabra inglesa queer se liga al siglo XVIII donde se empleaba para referirse al tramposo, al borracho y a la oveja negra, pero también a todo aquel que no se pudiese reconocer inmediatamente como hombre o mujer. Hoy se sigue usando como sustantivo para llamar al homosexual, como adjetivo para indicar lo torcido, lo raro, lo extraño, lo perverso, y como verbo para señalar aquello que frustra, inquieta, desconcierta. El término implica cierto rechazo. La palabra dejó de ser un instrumento de represión social para convertirse, empleada por el colectivo LGTBI, en un espacio de acción política. Queer representa las sexualidades, los afectos y los géneros que traspasan las fronteras de lo aceptado socialmente, aquello que impone el heteropartriarcado desde lo straight, lo "recto", relacionándolo con una vida heterosexual, monógama entre personas de la misma edad y clase social. La apropiación del insulto lo resignifica para usurpar los mecanismos de poder que se dirigen al cuerpo, a la vida. Así, las identificaciones negativas como "bolleras" o "maricones", sujetos abyectos que han estado ligados a una concepción del mal, de lo negativo, se convierten en un lugar de producción de identidades de resistencia a la normalización, al punto de vista "universal", a la historia blanca, colonial y hetero.

Para Preciado, "la multitud queer no se basa en una identidad natural (hombre/mujer), ni en una definición basada en las prácticas (heterosexuales/homosexuales) sino en una multiplicidad de cuerpos que se alzan contra los regímenes que les construyen como "normales" o "anormales" (Preciado, 2003, p. 164). Sólo cabe tomar la palabra, transformar el discurso imperante, entregarse a la resistencia.

\section{Referentes invertidos, la idea y los autores}

¿Cómo vincular una intervención en la Biblioteca Central con MARICÓN? Por el contexto, el Día del Libro, se nos ocurre reivindicar los nombres de tres autores gays. Estos autores debían reunir una serie de condiciones: I. Ser pioneros en su época y lugar de origen, publicando historias de hombres que mantienen sexo con oros hombres. II. Tener prestigio y calidad literaria. III. Que la biblioteca posea copias de sus obras. IV. Que escribiesen en catalán, castellano e inglés, respondiendo a la diversidad lingüística que se habla en la universidad.

Por cierto, al emprender esta nueva búsqueda, hallamos un test para descubrir si eres activo, pasivo o versátil. Una serie de preguntas que rozan lo absurdo, ligan una respuesta ruda con ser activo, una respuesta sumisa con ser pasivo, y una respuesta indiferente con ser versátil. En https://www.mtmad.es/firstdateslessons/TEST-gay-Activo-Pasivo-Versatil-primera-cita_0_2504775212.html (consultado el 3 de abril de 2019). 
Nos decantamos por William S. Burroughs, Pedro Lemebel y Terenci Moix. A continuación, describimos las razones:

\subsection{William S. Burroughs. Ser queer antes de la teoría queer ${ }^{7}$}

William S. Burroughs (Estados Unidos, 1914-1997) fue un novelista y ensayista. Su obra literaria destaca por una fuerte experimentación con el lenguaje. Nuestro primer contacto con su obra se produjo al leer El almuerzo desnudo (1959) a los veinte años. Nos conmocionó su manera de escribir, impenetrable, fragmentada ${ }^{8}$, contundente, con descripciones rotundas, sin filtro. Fue la primera vez que pudimos leer sobre maricas ${ }^{9}$ en una orgía de letras en las que se reiteraba la aparición de vergas y chaperos.

Quizá, el anclaje más evidente de Burroughs con nuestra investigación es la explicitud del título de su segunda novela, Queer ${ }^{10}$. Burroughs se apropia del insulto11 "queer" para revertirlo. Oliver Harris mantiene en el prólogo que escribe para Anagrama, que lo queer no se encuentra en la historia, sino en su modo de escribir, huyendo de un método narrativo heterosexual, subvirtiendo la propia escritura. (En Burroughs, 2018, p. 29). Concluye que no hay libros heterosexuales en la obra de Burroughs, cualquiera de sus libros podría haberse llamado Queer.

\subsection{Pedro Lemebel, La loca}

Pedro Lemebel (Santiago de Chile, 1952-2015) fue un escritor y artista que aúna géneros ${ }^{12}$ artísticos. Adoptó su apellido materno ${ }^{13}$. Quizá una de las primeras acciones que asume en su activismo. Regina Vanesa Cellino ve en ello un gesto de alianza con lo femenino (2015, p. 30), que con el tiempo se presenta bajo forma de lo travesti.

En 1987 forma en Santiago, junto a Francisco Casas, el grupo de performance Las Yeguas del Apocalipsis. En sus acciones ambos se travestían produciendo situaciones en las que reprobaban el régimen militar de la dictadura y su manera de imponerse sobre los cuerpos. Estos intereses se reflejan en su literatura. Lemebel se vale de la crónica, más cercana a la noticia, al manifiesto. Retrata lo que ocurre en los barrios marginales de Santiago. Con un lenguaje barroco e irreverente, se aproxima al cuerpo travestido de La Loca, figura principal de sus crónicas, una travesti que bien podría ser su alter ego. Así como su escritura se ornamenta y llena de artificios, se transforma la travesti para que, a través de su exclusión social, sus deseos y sus pasiones, emerja lo diferente como tema y denuncia. Con una función rebelde, retó a la sociedad que lo oprimía, posicionándose en contra de lo heteronormativo, reivindicando lo mestizo, lo indígena, lo proletario y lo gay.

\subsection{Terenci Moix, sueños de mariquita}

Terenci Moix ${ }^{14}$ (Barcelona, 1942-2003) fue un escritor catalán ${ }^{15}$ que se centró en lo autobiográfico -incide en la educación que recibió bajo valores religiosos y franquistas, y la homosexualidad-, y en la mitomanía que sentía hacia Egipto y las estrellas de Hollywood ${ }^{16}$.

Uno de los motivos por los cuales escogimos a Moix se debe a un factor puramente autorreferencial. Es el primer hombre que conocimos como personaje público abiertamente gay en España. Nuestro recuerdo se retrotrae a nuestra infancia, lo vimos en una de

\footnotetext{
${ }^{7}$ Esta es la apropiación de un título de Jorge Aloy (2016).

${ }^{8}$ Entonces desconocíamos que Burroughs trabajaba con el cut-up, una técnica creativa que desestructura el resultado, aunque nos cautivó su fuerza expresiva. El cut-up es una técnica literaria que corta un texto -propio o de otro- de forma aleatoria y lo reordena siguiendo esta estructura azarosa para conseguir un nuevo escrito, un nuevo sentido. Burroughs propone una metodología concreta para la obtención de un nuevo texto: cortar una página a lo largo y a lo ancho, reasignarle cuatro números, siguiendo el orden de la lectura. Colocar la parte 1 junto la 4 y la 3 junto a la 2 . También anima a hacerlo con fragmentos mucho más pequeños, para volver el mensaje ininteligible sin llegar cifrar el código (Burroughs, 2013).

${ }^{9}$ Palabra que usa continuamente.

${ }^{10}$ Inicialmente llamada Marica en castellano. Tras el éxito académico del término, la editorial Anagrama decide publicar la novela con el título en inglés (Aloy, 2016, p. 6).

${ }^{11}$ Retomar el vocablo que antes había sido usado para agredir y convertirlo en un calificativo positivo, tanto en cuanto se entiende que hay orgullo en él.

12 Entiéndase el juego de palabras que se establece al emplear la palabra "género" como disciplina, pero también haciendo alusión al desvanecimiento de fronteras entre lo masculino y lo femenino que se da en su obra.

${ }^{13}$ Su nombre original es Pedro Mardones Lemebel.

${ }^{14}$ Seudónimo. Su nombre original es Ramón Moix Meseguer.

${ }^{15}$ Cabe decir que sólo la mitad de sus libros los escribió en catalán.

${ }^{16}$ Reminiscencias de la importancia de iconos pop en la construcción de una personalidad queer también vemos en la obra de Roberta Marrero. En su cómic El Bebé Verde (2016), Marrero relata que ante un mundo que se decidía a devorarla por su diferencia, por haber nacido con unos genitales que no se correspondían con el reconocimiento ni la formación de su género, lo que hizo fue esconderse en las vidas de ídolos con los que se reconocía en su rebeldía. Cabe hacer una asociación parecida a la personalidad de Moix, quien en cierto sentido maquillaba la realidad sumergiéndose en el imaginario de esos otros relatos de lustre y fama.
} 
en sus múltiples colaboraciones en programas de televisión, su personalidad no respondía a comportamientos masculinos estandarizados. Al preguntar a nuestra madre por qué aquel señor de la tele actuaba de aquella forma, nos contestó "porque es 'mariquita". Para ella, ser "mariquita"17 era algo que producía tanto rechazo como risa. Su burla y condena remarcó el acto transgresor de un "mariquita" que defendía ante los demás algo que no aprobaba todo el mundo, ni en la esfera pública ni en la privada.

\section{El resultado}

La elección de estos autores supone tres acercamientos distintos a la visibilización de lo gay como temática. Buscamos los títulos que conforman sus bibliografías completas y le asignamos a cada uno un color secundario, para señalar la marginalidad de unos argumentos que nunca han estado en primer plano. El naranja para Burroughs, por ser el color de la portada de El almuerzo desnudo, la edición de Anagrama que leímos. Para Moix el verde, porque verdes eran las letras del título de la edición del Arpista ciego (2002), primer libro suyo que leímos. Y el violeta para Lemebel, por ser el color que se obtiene al combinar rojo y azul, los colores de la bandera de Chile.

En la sala de la segunda planta de la biblioteca construimos los apellidos en mayúsculas, seguidos, sin espacios, poniéndolos al mismo nivel. El orden se debe a un motivo totalmente compositivo, por formas y colores. Primero el naranja, luego el verde y por último el violeta. En cinco jornadas de ocho horas cada una, dibujamos, en primer lugar, los contornos de las letras con cinta de carrocero, con una altura de 2,37 m cada una. Luego las rellenamos, escribiendo a mano, con rotulador de tiza, los títulos que componen su obra completa. Desde el interior del edificio se tiene una visión perfecta de los nombres, pero están escritos al revés, aludiendo de este modo a lo "invertido" como un insulto del cual apropiarnos, complicándole las cosas al espectador. Desde fuera, las letras se presentan al derecho, sin embargo, las palmeras que se encuentran frente al edificio impiden su correcta lectura.
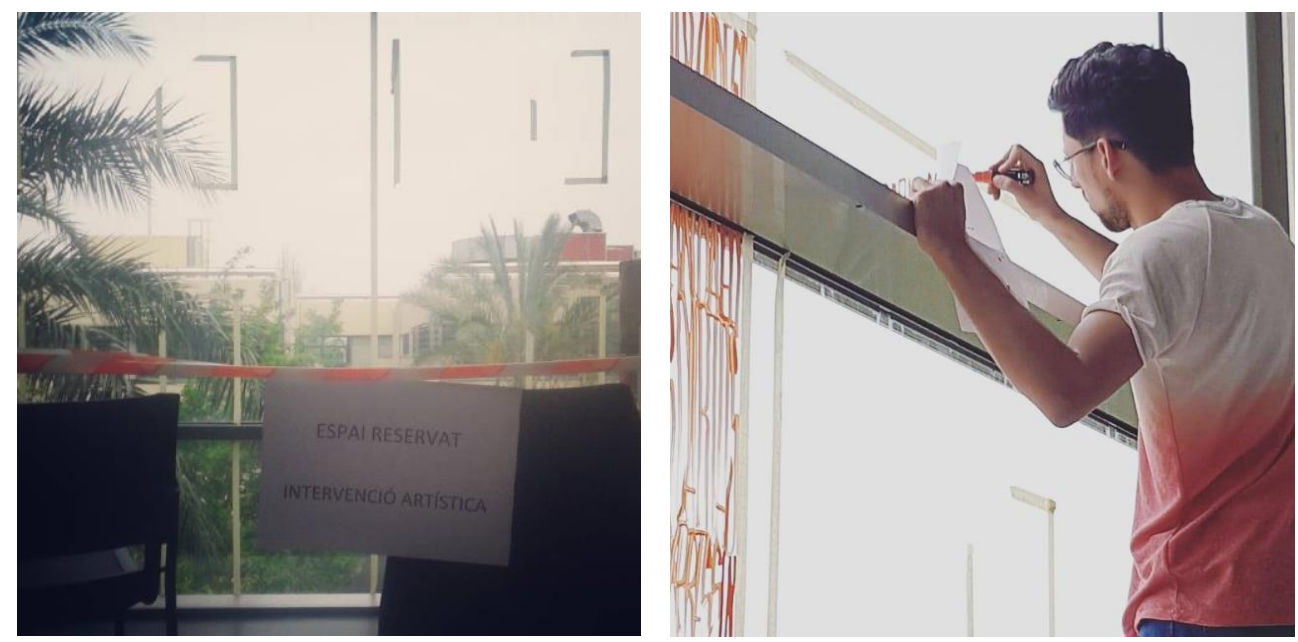

Figura 4. Proceso de producción de Referentes invertidos. Se reserva un espacio y se esboza las letras con cinta de carrocero.

Figura 5. Escribimos, con rotulador de tiza naranja, los títulos completos de William S. Burroughs en las cristaleras de la Biblioteca Central.

El resultado es una intervención de grandes dimensiones. De día, la luz traspasa el rotulador, y aquellos que se sientan cerca son bañados por la atmósfera que proyecta cada uno de los colores. De noche, la biblioteca se ilumina mientras todo permanece a oscuras en el exterior, vista desde el jardín, la cristalera se convierte en una enorme caja de luz, mostrando, como un luminoso, lo que antes se veía con dificultad.

\footnotetext{
${ }^{17}$ Nos lo definió como un hombre que desea tener de pareja a otro hombre.
} 
Referentes invertidos: intervención artística, teoría queer y literatura

IV Congreso INTERNACIONAL DE INVESTIGACIÓN EN ARTES VISUALES ANIAV 2019

IMAGEN [N] VISIBLE]

http://dx.doi.org/10.4995/ANIAV.2019.9589
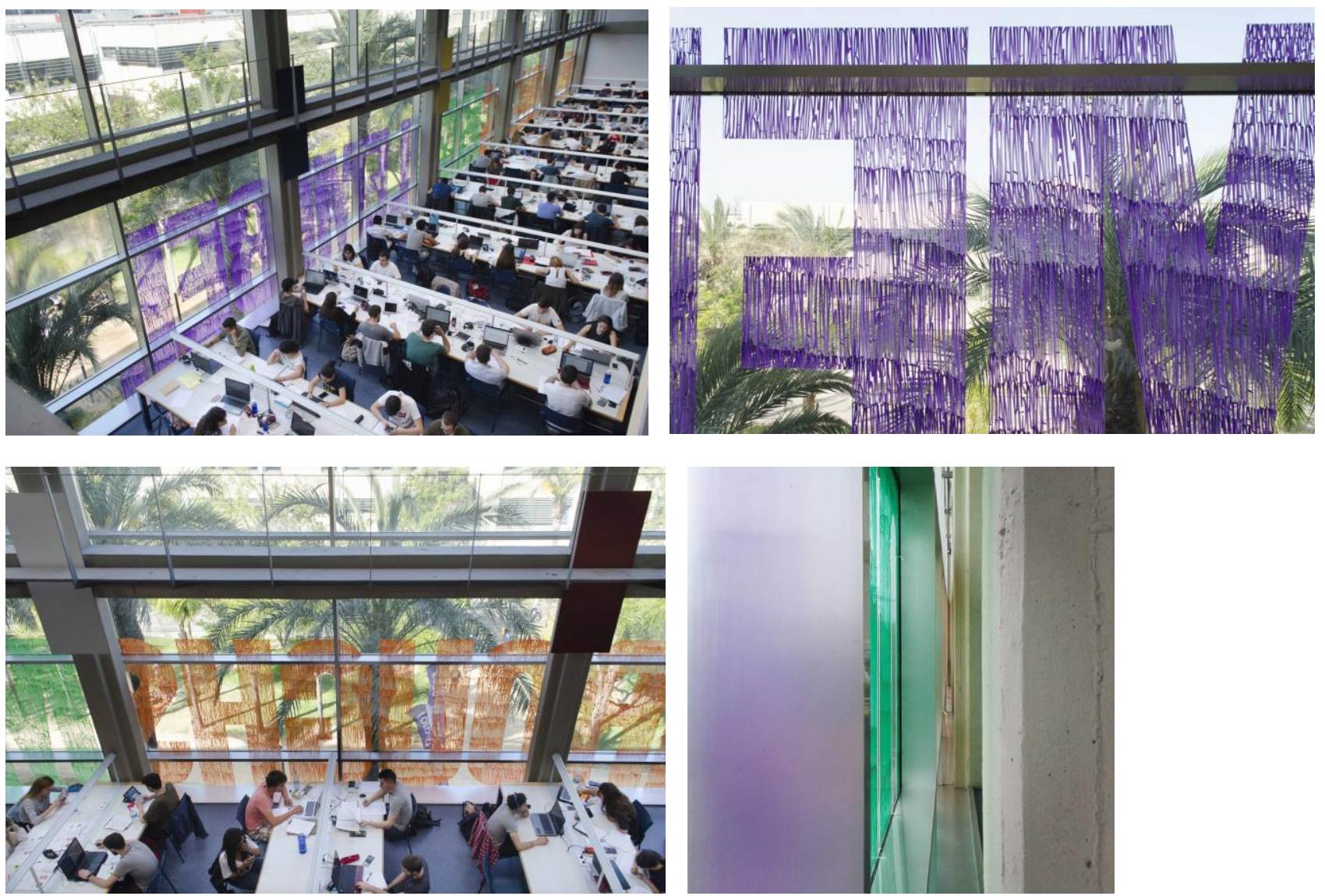

Figura 6A, 6B, 6C y 6D. Joaquín Artime, Referentes invertidos (2018). Vista interior de día de la intervención en la Biblioteca Central de la Universitat Politècnica de València. Rotulador naranja, verde y violeta sobre cristal. Los colores se reflejan sobre aquellas superficies que están más cerca.

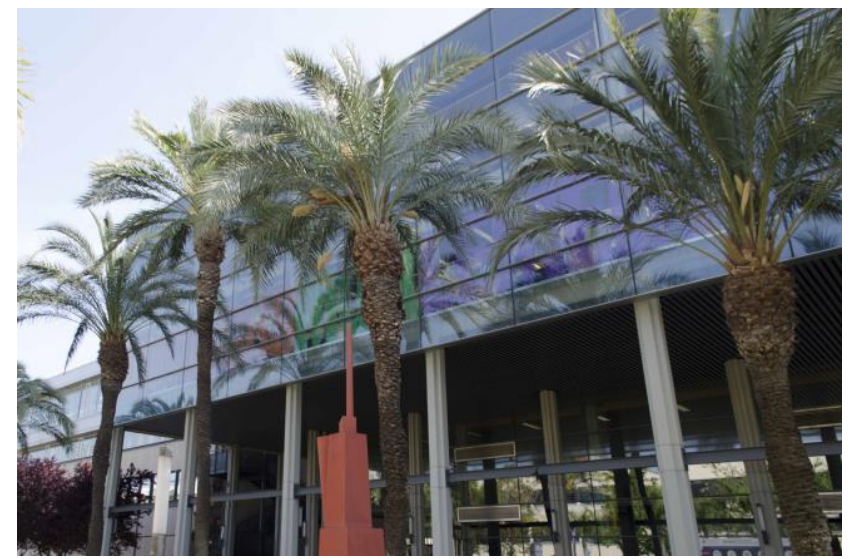

Figura 7. Joaquín Artime, Referentes invertidos (2018). Vista exterior de día de la intervención. Hay que esforzarse para leer las letras pese a que se encuentren al derecho. 
Referentes invertidos: intervención artística, teoría queer y literatura

IV Congreso INTERNACIONAL DE INVESTIGACIÓN EN ARTES VISUALES ANIAV 2019

IMAGEN [N] VISIBLE]

http://dx.doi.org/10.4995/ANIAV.2019.9589
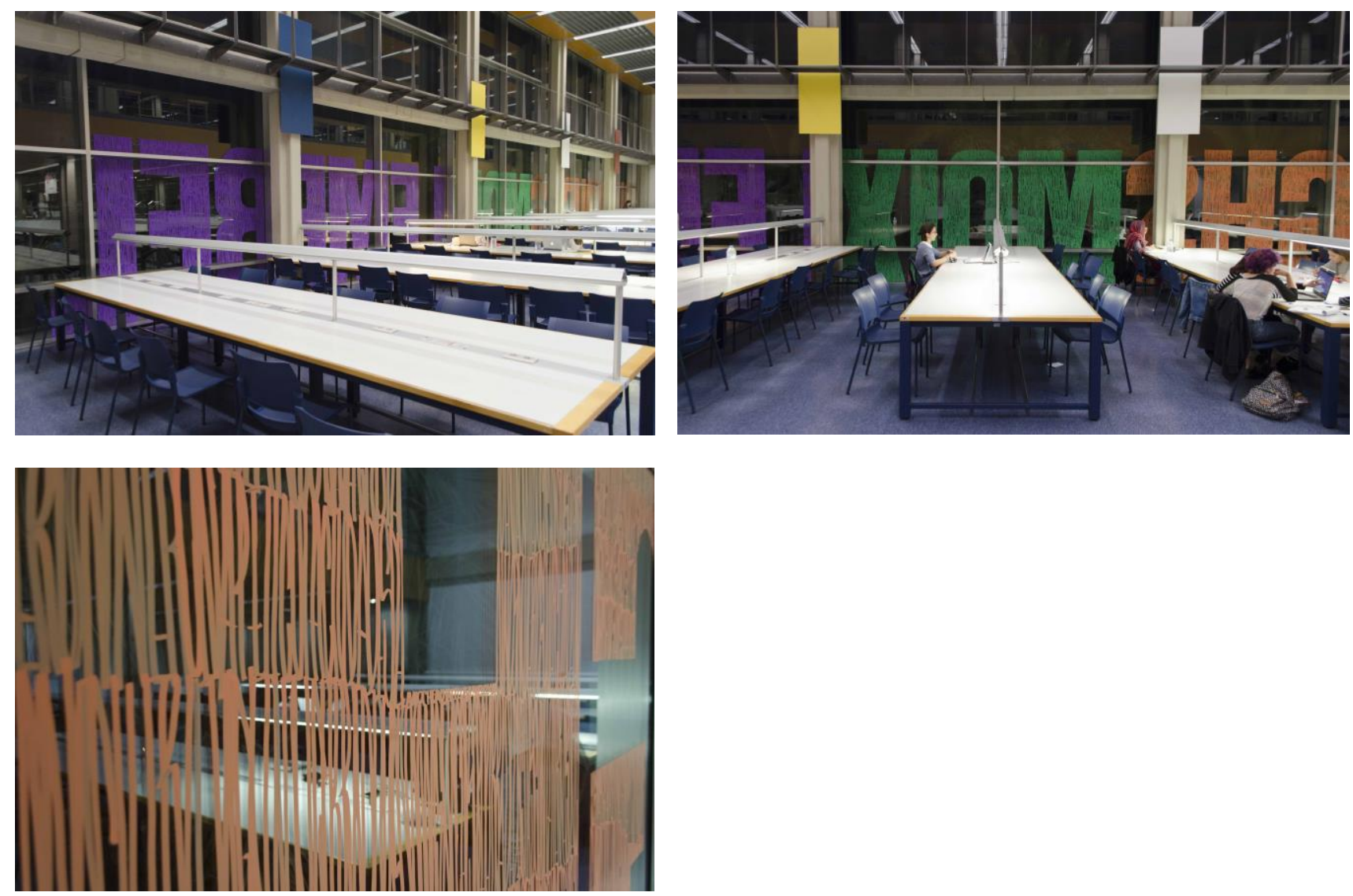

Figura 8A, 8B y 8C. Joaquín Artime, Referentes invertidos (2018). Vista interior de noche de la intervención. Los colores se ven más sólidos cuando no son atravesados por la luz solar.
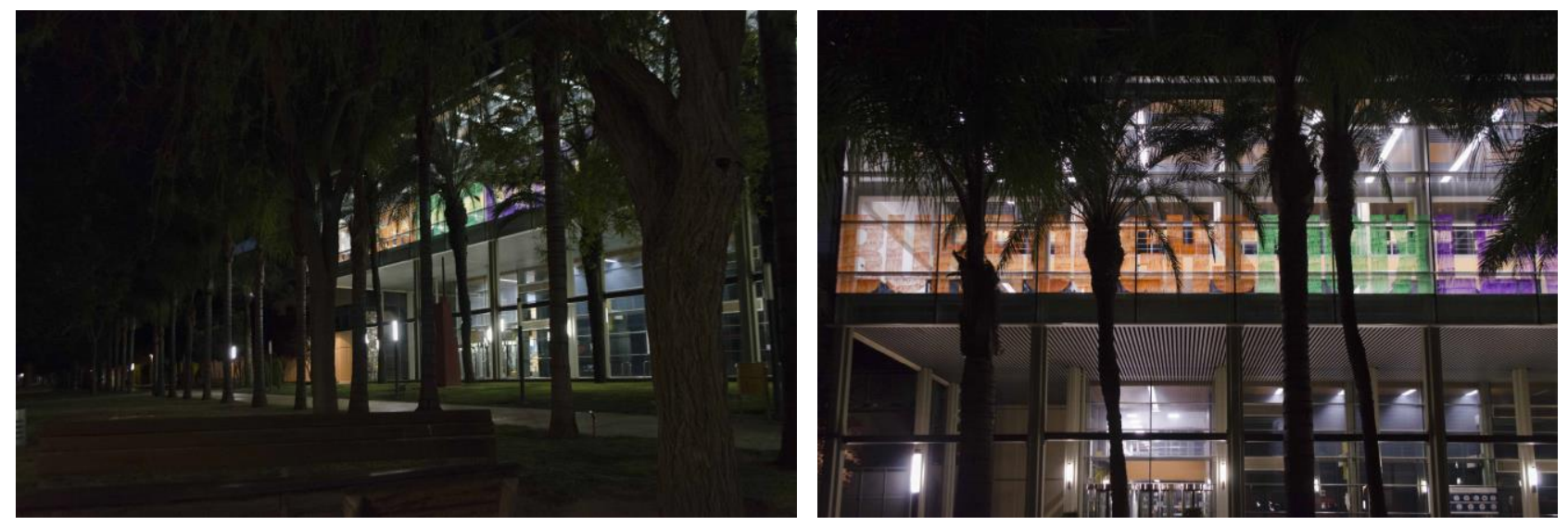

Figura 8A, $\mathbf{8 B}$ y $\mathbf{8 C}$. Joaquín Artime, Referentes invertidos (2018). Vista exterior de noche de la intervención. La biblioteca se convierte en una gran caja de luz, y en la oscuridad se muestran los nombres.

\section{CONCLUSIONES}

Con esta intervención damos continuidad a nuestra serie letanías, así como avanzamos en una línea de investigación comenzada en 2017, donde visibilizamos problemáticas queers adquiriendo un especial compromiso con lo gay. Vinculamos estos conceptos con el 
lenguaje, la palabra como forma plástica, la biblioteca y la literatura para que los nombres de unos autores, cuya importancia queremos reivindicar, se mantengan ininteligibles durante el día y se revelen con claridad por la noche.

Profundizamos en el uso de un espacio no expositivo para desarrollar una obra artística de grandes dimensiones que se relaciona con el mismo y con nuestros intereses. Después de tres meses de exposición, la dirección de la biblioteca decide no retirar la intervención. Sus características formales logran que la pieza se integre perfectamente con la arquitectura y la finalidad del edificio.

En definitiva, Referentes invertidos ofrece un lugar único a unos escritores que han creado desde el margen, perteneciendo a una minoría sexual. Con ello, se pone en valor y en común su producción literaria, su importancia histórica y sus aportaciones al mundo de las letras y al mundo queer.

\section{FUENTES REFERENCIALES}

Aloy, J. (2016). Queer de William S. B. Ser queer antes de la teoría queer. Álabe, 14, 1-8. https://10.15645/Alabe2016.14.1

Burroughs, W. S. (2013). La revolución electrónica. Buenos Aires, Argentina: Caja Negra Editora.

Burroughs, W. S. (2018). Queer. Barcelona, España: Editorial Anagrama.

Cellino, R. V. (2015). Performance: travestismos y política en las crónicas de Pedro Lemebel. Catedral Tomada Revista de Crítica Literaria Latinoamericana, 3 (4).

Gabaldón, C. (2018). Sujeto maricón. Aproximación desde la práctica artística a la construcción de un nuevo paradigma identitario (Trabajo Final de Máster). Universitat Politècnica de València, Valencia, España.

Marrero, R. (2016). El bebé verde: infancia, transexualidad y héroes del pop. Madrid, España: Lunwerg.

Preciado, B. (2003). Multitudes queer. Notas para una política de los "anormales". Revista Multitudes, (12), 157-66.

Rivas San Martín, F. (2018). Geolocalizar el cruising. Notas sobre Grindr y otras tecnologías del sexo gay. Multitud Marica. Activaciones de archivos sexo-disidentes en América Latina. Santiago de Chile, Chile: Museo de la Solidaridad Salvador Allende. 